\title{
Entomological Survey of Artificial Container Breeding Sites of Dengue Vectors in Batasan Hills, Quezon City
}

\author{
Maria Sonia S. Salamat, Kim L. Cochon, Gertrude Camille C. Crisostomo, \\ Pauline Beatriz S. Gonzaga, Nathanael A. Quijano, \\ Jennifer F. Torio and Aristea A. Villanueva
}

College of Public Health, University of the Philippines Manila

\begin{abstract}
Objective. Dengue fever remains a public health problem in the Philippines. Eliminating key container artificial breeding sites of mosquito vectors is a vital part of dengue control. The objective of this descriptive cross-sectional study was to conduct an entomological survey of artificial container breeding sites of Aedes mosquitoes in households of two puroks in Batasan Hills, Quezon City.

Methods. All potential artificial container breeding sites of dengue in each household were inspected for mosquito larvae. Water was sampled from all containers that had mosquito larvae and the larval species determined through microscopic examination. Using the World Health Organization list of recognized containers, each container was classified as a recognized container or an unrecognized container.
\end{abstract}

Results. The larval indices computed were: container index $=$ $6.4 \%$, household index $=23.9 \%$ and Breteau index $=29 \%$. The proportion of containers positive for $A$. aegypti larvae was significantly higher for the unrecognized containers $(9.9 \%)$ than that of the recognized containers $(3.9 \%)(p=0.002)$.

Conclusion. The high household index and Breteau index indicate that the potential for dengue transmission is high in the study area. Unrecognized artificial containers contributed significantly to the number of Aedes breeding sites. "Search-anddestroy" campaigns in the community should be expanded to include these containers. Crafting specific vector control messages that address the problem of particular unrecognized containers as well as those of recognized containers with the highest proportion positive for Aedes larvae will also aid dengue control and prevention. Repeat surveys to monitor larval indices may be used to help ascertain the effectiveness of these messages in decreasing mosquito breeding sites.

Key Words: dengue, vectors, mosquito, Aedes, survey

Corresponding author: Maria Sonia S. Salamat, MD

Department of Parasitology

College of Public Health

University of the Philippines Manila

Telephone: +632 5235929

Email: msssalamat@post.upm.edu.ph or/ sonia.salamat@gmail.com

\section{Introduction}

Dengue fever, a mosquito-borne disease caused by the dengue virus, remains a public health problem in the Philippines. The disease was ranked tenth in the country's 5year average morbidity data from 2000 to $2004 .{ }^{1}$ In 2001, an estimated 528 disability-adjusted life years (DALYs) were lost to dengue throughout the world. ${ }^{2}$ It has been demonstrated that the DALYs attributed to dengue nearly equaled the cumulative total DALYs for intestinal helminths, tuberculosis, malaria and the childhood disease cluster in Latin America and the Carribean. ${ }^{2}$ The more severe forms of the disease are potentially fatal, as they are associated with bleeding complications and shock. . $^{3,4}$

The primary vector of dengue is Aedes aegypti while Aedes albopictus serves as a secondary vector. ${ }^{2}$ Aedes mosquitoes lay their eggs in clean, stagnant water. ${ }^{3,5} A$. aegypti exhibits a preference for breeding in wateraccumulating and water-holding artificial containers found within households. ${ }^{5}$ A. albopictus was previously observed to exclusively breed in natural containers; however, recent studies have shown that A. albopictus breeds in artificial containers as well. ${ }^{6,7}$

The elimination of key artificial container breeding sites is regarded as one of best approaches for the prevention of dengue. ${ }^{8}$ This strategy is part of "search-and-destroy" campaigns conducted for dengue prevention and control. Key containers differ from place to place..$^{9,10}$ By detecting previously unrecognized key containers, expansion of the coverage of "search-and-destroy" campaigns becomes possible. The reduced mosquito population resulting from the conduct of "search-and-destroy" campaigns will decrease vector-host contact, thus aiding dengue prevention. ${ }^{9,11,12}$

The World Health Organization (WHO) Guidelines on Dengue Surveillance and Mosquito Control lists recognized containers that have been established to be the usual breeding sites of dengue mosquito vectors (Table 1). Water tanks, drums, vases, pots, tin cans, pools, roof gutters, animal water containers, tires, discarded appliances, buckets, and ant traps are on this list.6,12 
Table 1. List of WHO recognized artificial container breeding sites of dengue vectors ${ }^{6}$

\begin{tabular}{lll}
\hline \multicolumn{2}{c}{ Recognized containers according } & to $\mathbf{W H O}^{6}$ \\
\hline Uncovered water tanks & Roof gutter & $\begin{array}{l}\text { Ram barrels for } \\
\text { collecting rainwater }\end{array}$ \\
$\begin{array}{l}\text { Metal drums for water } \\
\text { storage }\end{array}$ & $\begin{array}{l}\text { Animal water } \\
\text { container }\end{array}$ & $\begin{array}{l}\text { Earthen water storage } \\
\text { jars }\end{array}$ \\
Vases & Discarded tires & $\begin{array}{l}\text { Concrete water storage } \\
\text { tanks for bathrooms }\end{array}$ \\
Pots & Discarded & Plastic containers \\
aiscarded bottles and tin & Buckets & Water trays of \\
cans & Antrigerators \\
Pools & Air conditioner trays \\
$\begin{array}{l}\text { Saucers for ornamental } \\
\text { potted plants }\end{array}$ & & \\
\hline
\end{tabular}

Entomological surveys are primarily conducted to measure the relative presence of disease-carrying arthropod vectors. ${ }^{13}$ The conduct of these surveys is recommended in countries endemic for dengue because survey results are useful for identifying possible causes of dengue outbreaks, ${ }^{9}$ for identifying key containers, $, 5,8,9,14$ and for identifying new breeding sites of vectors. 3,14 A survey is conducted by searching 100 or more households for possible breeding sites of vectors. In each household, all water-holding containers are examined, and water is sampled to detect the presence of vector larvae. Species identification is made after examination of larvae in the laboratory. 6,15

Larval surveys utilize the Breteau index (BI), house index (HI) and container index (CI). BI refers to the number of larvae-positive artificial containers per 100 houses inspected. HI refers to the proportion of households with larvae-positive containers. The CI is the proportion of larvaepositive containers. The BI is regarded as the single most useful index for estimating Aedes density in an area because it is able to demonstrate a relationship between larvaepositive containers and the number of households. $\mathrm{HI}$ is used to determine the presence and distribution of Aedes in a locality and indicates that dengue virus may potentially spread in an area once a case becomes established. According to $\mathrm{WHO}$ guidelines, a $\mathrm{HI}>5 \%$ and/or a $\mathrm{BI}>20$ in any area is a sign that the area is "dengue-sensitive", meaning that the risk of dengue transmission is high. ${ }^{6}$ The $\mathrm{HI}$ and $\mathrm{BI}$ are frequently used to determine priority areas for the implementation of control measures. ${ }^{6}$

Barangay Batasan Hills in Quezon City, Philippines, is a highly urbanized and densely populated area where one of the highest incidence rates of dengue was observed in $2010 .^{16}$ In 2010, the barangay had a population of 150,764 and had the second largest population among all the barangays in Quezon City. ${ }^{17}$ Residents in many parts of the area have to contend with poor living conditions, overcrowded households, high volumes of garbage, and substandard water supply systems that make it necessary to store water in tanks and barrels. In 2011, the water supply in Batasan Hills was available for only 8 to 12 hours a day. ${ }^{18}$ These environmental conditions favor the breeding of dengue mosquito vectors that may prompt increased dengue transmission. In 2010, Batasan Hills was designated by the Philippine Department of Health (DOH) as a dengue "hotspot", a term applied to an area where clustering of dengue cases as well as an increasing number of cases have been observed for two consecutive weeks. ${ }^{16}$ In the week from July 31 to August 6, 2011, the area was once more reported by the $\mathrm{DOH}$ as a dengue hotspot. ${ }^{19}$

The objective of this descriptive cross-sectional study was to conduct an entomological survey of artificial container breeding sites of $A$. aegypti and $A$. albopictus in households of two puroks (subdivisions of the barangay, the smallest administrative unit) in Batasan Hills, Quezon City.

\section{Methods}

Two puroks, Purok Ruivivar and Purok Baldago from Cluster VII, Barangay Batasan Hills, Quezon City were chosen as the sampling sites because the number of dengue cases recorded from these puroks for the first half of 2011 were among the highest for the Batasan Hills puroks, based on the review of records available at the barangay health center. Cluster VII is considered an urban poor community.

The study employed a one-stage stratified cluster systematic sampling design. The sampling unit was the household, defined as one unit of accommodation. The computed sample size was 162 households after taking into account an anticipated non-response rate of $10 \%$. A total of 142 households were surveyed. The elementary unit comprised water-holding containers and artificial materials capable of accumulating water indoors and outdoors.

\section{Household inspection}

In each household, inspection for all potential artificial container breeding sites of dengue vectors was performed. Every room of each household was searched systematically for containers. The surrounding area of the household within a 5-meter distance from each wall of the house was also inspected for artificial containers.

All artificial containers were inspected for the presence of mosquito larvae through gross examination with the unaided eye. A flashlight was used for dark-colored containers in which mosquito larvae were more difficult to see. The number of containers inspected, type of containers, and the number of containers with at least one mosquito larva were recorded. Using the WHO list of recognized containers $^{6}$ (Table 1), each container inspected was classified as either a recognized container or an unrecognized container. 


\section{Sample collection}

Water samples were collected only from containers that had mosquito larvae. For containers with a maximum volume of $500 \mathrm{ml}$, all the water contents of the containers were transferred to a labeled plastic bag. Dechlorinated water was added to the samples to prevent larvae from drying. For containers that held more than $500 \mathrm{ml}$ of water, three representative samples were collected by the use of a standard entomological white and opaque dipper. The dipper was completely submerged in the container for less than 1 second to avoid disturbing the mosquito larvae and causing them to dive below the surface. All samples were transported to the laboratory for identification.

\section{Laboratory identification}

Larvae that were already at the fourth instar larval stage upon collection were immediately examined under a microscope to determine the species. Larvae collected at an earlier stage of development were reared in white plastic bowls to the fourth instar larval stage to enable species differentiation with the aid of a microscope. Upon reaching the fourth instar stage and prior to examination, larvae were killed by pouring hot water into the bowls containing them. Using a pipette, the larvae were aspirated from the water and mounted onto glass slides. By examining the characteristics of the comb scales found on the eighth abdominal segment of the mosquito larvae using the World Health Organization guide, ${ }^{6}$ species differentiation was achieved. Containers that held at least one larva of either $A$. aegypti or A. albopictus were classified as positive. Containers that did not have any larvae or contained only non-Aedes larvae were classified as negative containers.

Figure 1 diagrams the process of data collection.

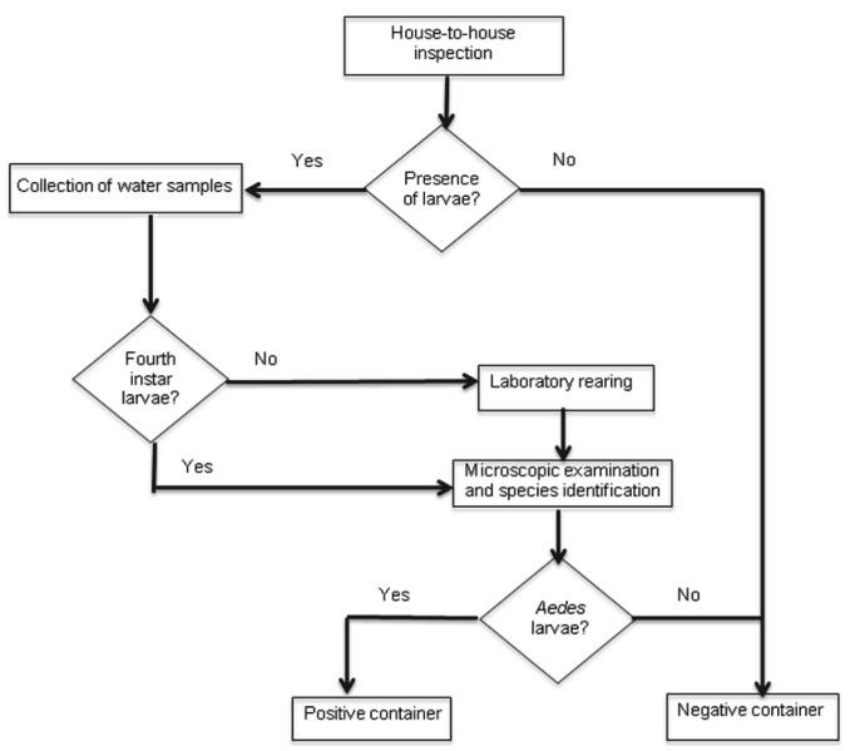

Figure 1. Process of data collection

\section{Data analysis}

Descriptive statistics, i.e., frequency and percentage distributions, were util ized to describe the containers identified in this survey. The BI, HI and CI for each type of container were computed using the following formulas:

$\mathrm{CI}=$ number of positive containers $x 100$ total number of container breeding sites inspected

$H I=$ number of houses positive for Aedes larvae $\times 100$ total number of households inspected

$\mathrm{BI}=$ number of positive artificial containers $\times 100$ total number of households inspected

The computed values were used as point estimates for generalizing the indexes to the target population. The $90 \%$ confidence interval estimates of the indexes were also computed using the following general formula for estimating the population proportion:

$$
\hat{p} \pm Z \cdot \sqrt{\frac{\hat{p}(1-\hat{p})}{n}}
$$

Meanwhile, the chi-square test of homogeneity was performed to compare the proportion of positive containers between the recognized and unrecognized containers. A 5\% level of significance was used in making decisions for the hypotheses tested.

Microsoft Excel was used to encode the data and calculate descriptive statistics. OpenEpi v.2.3.1 (www.openpi.com) was employed in the computation of the interval estimates of the larval indices. Stata v.12 (StataCorp, College Station, Texas) was used to perform the chi-square test.

\section{Ethics statement}

The University of the Philippines College of Public Health Ethics Review Board reviewed and approved the research protocol before it was implemented. The investigators obtained informed consent from a member of each household prior to the conduct of the larval survey.

\section{Results}

Among 142 houses searched, 34 (23.9\%) were found to have artificial containers that harbored $A$. aegypti larvae. Among 645 water-holding containers inspected, 41 (6.4\%) were found to have $A$. aegypti larvae (Table 2). Four types of unrecognized artificial containers were found to be positive for A. aegypti larvae. Culex larvae were also detected in the study sites. A. albopictus and Anopheles larvae were not detected. 
Table 2. Types of containers inspected and percentage positive for Aedes larvae

\begin{tabular}{|c|c|c|c|}
\hline Type of container & $\begin{array}{c}\text { Total } \\
\text { number of } \\
\text { containers } \\
\text { inspected }\end{array}$ & $\begin{array}{c}\text { Number of } \\
\text { positive } \\
\text { containers }\end{array}$ & $\begin{array}{c}\text { Percentage of } \\
\text { positive } \\
\text { containers }\end{array}$ \\
\hline \multicolumn{4}{|l|}{ Recognized containers } \\
\hline Metal drum & 164 & 11 & 6.7 \\
\hline Pots, vases, tin cans & 16 & 2 & 12.5 \\
\hline Bucket & 195 & 1 & 0.5 \\
\hline Animal water container & 8 & 1 & 12.5 \\
\hline $\begin{array}{l}\text { Total recognized } \\
\text { containers }\end{array}$ & 383 & 15 & 3.9 \\
\hline \multicolumn{4}{|l|}{ Unrecognized containers } \\
\hline Dish organizer tray & 83 & 22 & 26.5 \\
\hline Drum cover & 15 & 2 & 13.3 \\
\hline Mugs in storage & 3 & 1 & 33.3 \\
\hline Fountain & 1 & 1 & 100 \\
\hline Basin & 70 & 0 & 0 \\
\hline Bottle & 22 & 0 & 0 \\
\hline Soap dish & 11 & 0 & 0 \\
\hline Utensils holder & 11 & 0 & 0 \\
\hline Dipper & 10 & 0 & 0 \\
\hline Toothbrush holder & 10 & 0 & 0 \\
\hline Water dispenser & 7 & 0 & 0 \\
\hline Aquarium & 4 & 0 & 0 \\
\hline Cups container & 3 & 0 & 0 \\
\hline Bucket cover & 3 & 0 & 0 \\
\hline Well & 3 & 0 & 0 \\
\hline Container for baby bottles & 2 & 0 & 0 \\
\hline Bowl & 1 & 0 & 0 \\
\hline Shoe & 1 & 0 & 0 \\
\hline Toilet brush holder & 1 & 0 & 0 \\
\hline $\begin{array}{l}\text { Total unrecognized } \\
\text { containers }\end{array}$ & 262 & 26 & 9.9 \\
\hline Total & 645 & 41 & 6.4 \\
\hline
\end{tabular}

\section{Container index}

With 41 out of 645 containers positive for $A$. aegypti larvae, the CI was $6.4 \%$. Unrecognized positive containers were more numerous than recognized positive containers (Figures 2 and 3). Four types of recognized and 19 types of unrecognized artificial containers were inspected. Each of the four types of recognized containers had at least one container that was positive for A. aegypti larvae. On the other hand, at least one container was positive for larvae in 4 of 19 unrecognized container types (Table 2).

Drums were the recognized artificial container with the greatest proportion of positive individual containers. Of the unrecognized containers, $9.9 \%$ were positive for A. aegypti larvae, compared with only $3.9 \%$ of recognized containers. About two-thirds of all positive containers were unrecognized containers (Table 3).

\section{House index}

With 34 out of 142 households having containers positive for $A$. aegypti larvae, the $\mathrm{HI}$ was $23.9 \%$. Figure 4 shows the distribution of households in terms of the status of the containers examined (positive or negative), as well as the classification of the positive containers found.

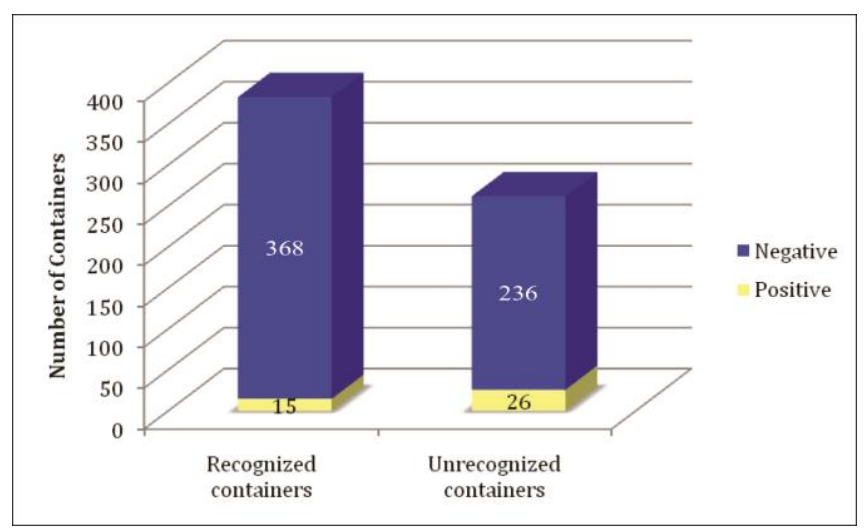

Figure 2. Distribution of containers according to type and positivity for Aedes larvae

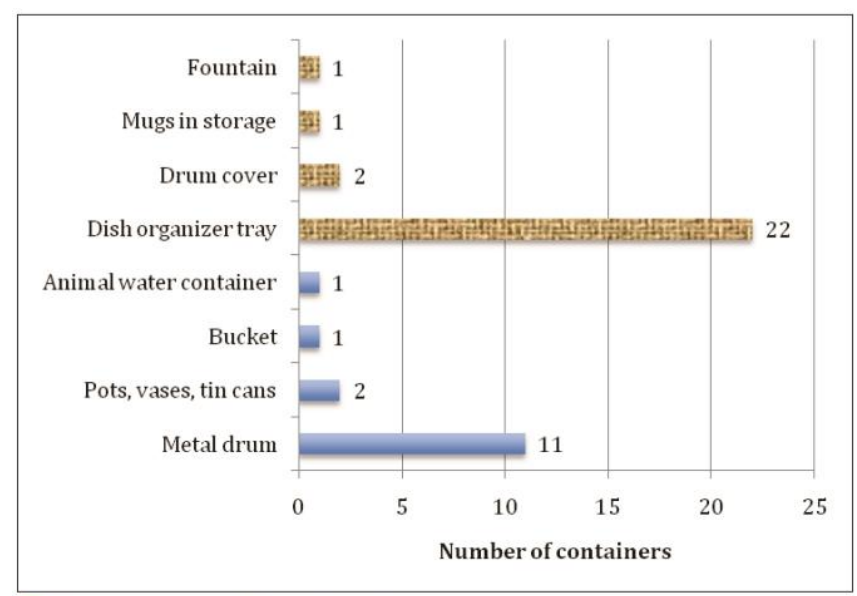

Unrecognized containers $\square$ Recognized containers

Figure 3. Frequency distribution of unrecognized and recognized containers positive for Aedes larvae

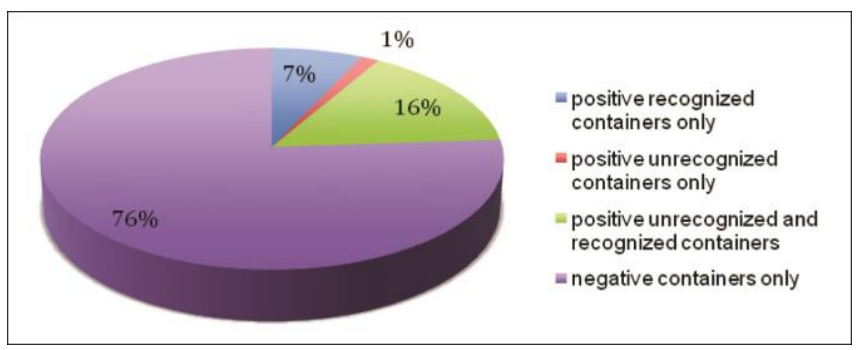

Figure 4. Distribution of households $(\mathrm{N}=142)$ in terms of positivity for Aedes larvae and type of containers identified within 
Table 3. Number of positive containers classified as recognized and unrecognized

\begin{tabular}{lcc}
\hline $\begin{array}{c}\text { Container } \\
\text { classification }\end{array}$ & $\begin{array}{c}\text { Number of positive } \\
\text { containers }\end{array}$ & $\begin{array}{c}\text { Percentage of } \\
\text { positive containers }\end{array}$ \\
\hline Recognized & 15 & 36.6 \\
Unrecognized & 26 & 63.4 \\
Total & 41 & \\
\hline
\end{tabular}

\section{Breteau index}

Among 142 households, 41 positive artificial containers were found, yielding a BI of 29 artificial containers per 100 households.

Table 4 summarizes the three larval indices in the entomological survey.

Table 4. Summary of larval indices at $90 \%$ confidence level

\begin{tabular}{lcc}
\hline Larval index & Point estimate & Interval estimate $\mathbf{( 9 0} \% \mathbf{C I})$ \\
\hline Container index & 6.4 & $4.78,7.94$ \\
Household index & 23.9 & $18.05,29.83$ \\
Breteau index & 29 & $22.62,35.13$ \\
\hline
\end{tabular}

\section{Discussion}

The container types with the highest percentage of positive containers were dish organizer trays, drum covers, mugs in storage, plant pots, vases, tin cans, and animal water containers. Approximately half of all the containers surveyed were buckets and metal drums for storing water, both of which are WHO recognized containers. However, the proportion of positive containers among buckets and drums was only $0.5 \%$ and $6.7 \%$, respectively. It is possible that water stored in these containers is used up and changed frequently owing to the irregular piped water supply in the area, ${ }^{18}$ making the containers less favorable as mosquito breeding sites.

The proportion of positive containers that are not in the WHO list of recognized containers (i.e., unrecognized) is 2.5 times that of positive recognized containers. Of the recognized containers, only 3.9\% were positive for Aedes mosquito larvae, in contrast with $9.9 \%$ of the unrecognized containers (Figure 2). Furthermore, the chi-square test shows that the proportion of positive containers is significantly higher for the unrecognized containers than for the recognized containers $(p=0.0002)$. This demonstrates that the problem created by the presence of unrecognized containers that serve as mosquito breeding sites may be as important as that from recognized containers. Dish organizer trays topped the list of unrecognized containers that were positive for Aedes larvae (Figure 3). A possible reason for this finding is that residents may have lacked the awareness that these trays, though shallow, can accumulate and hold water long enough to serve as mosquito breeding sites. Another plausible reason is that dengue prevention campaigns in the area may have put greater focus on better-known mosquito breeding sites such as vases, water storage containers, old tires, and empty bottles and cans. ${ }^{20}$ These proposed reasons may also explain the fact that a higher percentage of drum covers was positive for Aedes larvae compared to the drums themselves.

The term "key containers" has been applied to containers in households that consistently serve as the chief source of dengue mosquito vectors. ${ }^{8}$ Identifying these key containers has facilitated the crafting of mosquito control messages that are specific for each type of container. This strategy has been identified as a best practice in the prevention and control of dengue in the Americas ${ }^{8}$ and Australia. ${ }^{10}$ Data from this study can therefore be used to help formulate specific messages that pertain to dish organizer trays, drum covers, mugs in storage, vases, tin cans, and animal water containers, all of which showed the greatest proportions positive for Aedes larvae.

A $\mathrm{BI}>20$ is an indicator that a locality is denguesensitive, which means that the potential for transmission is high when a dengue case becomes established in the area ${ }^{2,5,21}$ (Table 5). The BI of 28.8 obtained in this study describes the risk of transmission of dengue in the study area as intermediate between low and high. ${ }^{2,21}$ The HI of $23.9 \%$ is evidence of a high risk of transmission (Table 5). It is important that the $\mathrm{HI}$ and $\mathrm{BI}$ be considered together because the $\mathrm{HI}$ provides information regarding the distribution of the positive containers within the households that are taken into account in determining the BI.

Table 5. Epidemiological interpretations of $\mathrm{HI}$ and $\mathrm{BI}^{6,22}$

\begin{tabular}{lcc}
\hline $\begin{array}{c}\text { Entomological } \\
\text { Indices }\end{array}$ & $\begin{array}{c}\text { High Risk of } \\
\text { Transmission }\end{array}$ & $\begin{array}{c}\text { Low Risk of } \\
\text { Transmission }\end{array}$ \\
\hline Breteau Index & $>50$ & $<5$ \\
House Index & $>10 \%$ & $<1 \%$ \\
\hline
\end{tabular}

Given the findings of this study, the conduct of campaigns that contain messages specifically addressing the problem of unrecognized and recognized key containers in the study area is recommended. Performing a repeat survey afterwards to check for an improvement in the larval indices may help determine the effectiveness of the campaigns.

\section{Limitations}

The study did not include artificial containers in less accessible areas of the households such as roofs and roof gutters in the survey. This may have resulted in an underestimation of the larval indices. Other unrecognized containers may also have been missed as a result.

\section{Conclusion}

The high $\mathrm{HI}$ and $\mathrm{BI}$ indicate that the potential for dengue transmission is high and that the potential for a dengue outbreak is high in the study area, indicating the need for strengthening dengue control and prevention measures. Unrecognized artificial containers were found to 
contribute significantly to the number of positive containers. "Search-and-destroy" campaigns in the community should be expanded to include these unrecognized containers. Formulating specific vector control messages that address the problem of particular unrecognized containers, as well as those of recognized containers with the highest proportion positive for Aedes larvae will also aid dengue control and prevention. Repeat surveys to monitor larval indices may be used to help ascertain the success of these messages in decreasing mosquito breeding sites, as well as to generate useful information for refining future dengue control and prevention campaigns.

\section{Acknowledgments}

The authors thank Hon. Ranulfo Ludovica, Mr. Larry Baldago, Mr. Zaldy Ruivivar, Ms. Joy Albay and the barangay officers of Batasan Hills for supporting the conduct of this study. The authors also thank Dr. Arlene Bertuso and Ms. Myra Mistica of the U.P. College of Public Health for sharing their expertise in entomology.

\section{References}

1. Department of Health-Philippines. Leading causes of morbidity [Online]. [cited 2011 Oct]. Available from http://www.doh.gov.ph/kp/statistics/morbidity.html\#2005.

2. World Health Organization. Vector surveillance and control 2003 [Online]. [cited 2011 Oct]. Available from http://www.who.int/csr/resources/publications/dengue/048-59.pdf.

3. World Health Organization. Dengue: Guidelines for diagnosis, treatment, prevention and control, 2009 ed [Online]. [cited 2011 Oct]. Available from http://whqlibdoc.who.int/publications/ 2009/9789241547871_eng.pdf.

4. Department of Health. Dengue: Transmission, signs and symptoms, prevention and control [Online]. [cited 2011 Oct]. Available from http://www.doh.gov.ph/healthadvisories/dengue/.

5. Cruz E, Salazar F, Porras E, Mercado R, Orais V, Bunyi J. Entomological survey of dengue vectors as basis for developing vector control measure in Barangay Poblacion, Muntinlupa City, Philippines. Dengue Bulletin. 2008; 32:167-70

6. World Health Organization. Guideline for dengue surveillance and mosquito control, $2^{\text {nd }}$ ed; 2003 [Online]. [cited 2011 Oct]. Available from www.wpro.who.int/publications/pub_9290610689/en/index.html.

7. Gerberg EJ. Manual for mosquito rearing and experimental techniques. American Mosquito Control Association, Inc. Selma, California; 1979 [Online]. [cited 2011 Oct]. Available from http://www.mosquitocatalog.org/files/pdfs/048499-0.pdf.

8. Lloyd L. Best practices for dengue prevention and control in the Americas: Washington DC, Office of Health, Infectious Disease and Nutrition Bureau for Global Health U.S. Agency for International Development; 2003.

9. David MR, Lourenço-de-Oliveira R, Freitas RM. Container productivity, daily survival rates and dispersal of Aedes aegypti mosquitoes in a high income dengue epidemic neighbourhood of Rio de Janeiro: presumed influence of differential urban structure on mosquito biology. Mem Inst Oswaldo Cruz. 2009; 104(6):927-32.

10. Montgomery BL, Ritchie SA. Roof gutters: a key container for Aedes aegypti and Ochlerotatus notoscriptus (Diptera: Culcidae) in Australia. Am J Trop Med Hyg. 2002; 67(3):244-6.

11. Santos SRA, Melo-Santos MAV, Regils L, Albuquerque CMR. Field evaluation of ovitraps consociated with grass infusion and Bacillus thuringiensis var. israelensis to determine oviposition rates of Aedes aegypti. Dengue Bulletin. 2003; 27:156-162.
12. Yaacob N. The seasonal abundance of Aedes (Stegomyia) albopictus (Skuse) (Diptera: Culcidae) in Universiti Sains Malaysia Campus [MS thesis]. University Sains Malaysia; 2006.

13. World Health Organization. Prevention and control of dengue and dengue haemorrhagic fever comprehensive guidelines. WHO Regional Publication SEARO No. 29.

14. Barrera R, Amador M, Diaz A, Smith J, Munoz-Jordan JL, Rosario Y. Unusual productivity of Aedes aegypti in septic tanks and its implications for dengue control. Med Vet Entomol. 2008; 22(1):62-9.

15. Washington State Department of Health Zoonotic Disease Program. Guidance for surveillance, prevention, and control of mosquito-borne disease, 2008 ed.

16. Department of Health National Epidemiology Center. Disease surveillance report. [Online]. September 26 - October 2, 2010 [cited 2011 Oct]. Available from http://www.doh.gov.ph/sites/default/ files/2010Den39WMR.pdf.

17. National Statistics Office Philippines. Quezon City Fact Sheet July 2012 [Online]. [cited 2013 May]. Available from http://nso-ncr2.ph/wpcontent/uploads/2012/08/Quezon-City-Factsheet_July-2012.pdf.

18. Guzman JI for the Philippine Information Agency. Maynilad upgrades 'North C' pumping station in QC [Online]. [cited 2013 June]. Available from http://www.pia.gov.ph/news/index.php?article=241350351799.

19. Department of Health Philippines-National Epidemiology Center. Disease surveillance report [Online]. July 31 - August 6, 2011 [cited 2011 Oct]. Available from http://www.doh.gov.ph/sites/default/ files/2011Den31WMR.pdf.

20. Department of Health Philippines. Dengue advisory Mag 4S laban sa dengue poster [Online]. [cited 2013 June]. Available from http://www.shygirlsown.info/2011/07/deped-supports-4s-laban-sadengue.html.

21. Kantachuvessiri A. Dengue hemorrhagic fever in Thai society. Southeast Asian J Trop Med Public Health. 2002; 33(1):56-62. 